\title{
Objectifs financiers atteints sans budget global!
}

\section{Jürg Schlup}

Dr méd., président de la FMH

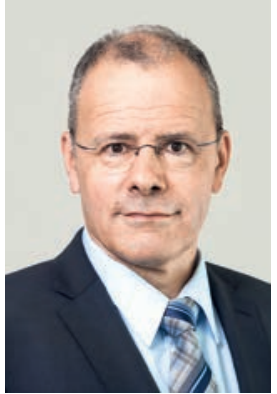

Références

1 OFS, 11.6.2019. Communiqué de presse:

dépenses de santé 2017: 82,5 milliards de francs au total.

2 Santésuisse, 17.6.2019. Communiqué: Fin du répit pour les payeurs de primes. Sans renversement de situation, une nouvelle augmen tation des coûts menace.

3 Santésuisse. Présentation lors de la conférence de presse du 17.6.2019: Evolution des coûts de la santé des dernières an nées et estimations pour 2019 et 2020 (page 7).

4 Rapport du groupe d'experts, 24.8.2017. Mesures visant à freiner la hausse des coût dans l'assurance obligatoire des soins.

5 Watson, 12.7.2017.

Santésuisse table en

2018 sur une augmentation des primes de 4 à 5 pour cent.

6 Tagesanzeiger, 28.9.2017, So stark steigen die Krankenkassenprämien 7 Handelszeitung, 4.2.2019, Steigende Gesundheitskosten 2018 gebremst.

8 OFS, 23.11.2018. Com muniqué de presse: La hausse des primes entre 2017 et 2018 réduit la progression du revenu disponible de 0,3 point.

9 Pius Gyger (2018)

Helsana Rapport sur les primes. 20 années

de primes: faits et

chiffres.
Cette année, l'Office fédéral de la statistiques (OFS) a ouvert la discussion sur les primes avec une information réjouissante: les dépenses de santé en 2017 ont augmenté de 2,6\% par rapport à l'année précédente, soit «une hausse [...] inférieure à la tendance des cinq dernières années $(+3,4 \%)$ » [1]. Il en est de même pour les coûts de la santé financés par l'assurance obligatoire des soins (AOS). Peu après, santésuisse entérinait: «avec 1,7\% en 2017 et $1 \%$ en 2018, la hausse a été nettement inférieure à celles des années précédentes» [2].

Pourtant, ce sont les estimations pessimistes qui ont fait les manchettes. L'interprétation de la faîtière des assurances, selon laquelle il s'agissait d'un "répit» avant le retour d'une "forte croissance des coûts» [3], a été reprise dans les médias, qui ont misé sur un "choc des primes» et une "envolée des coûts», de 3\% (selon santésuisse) ou d'un peu moins de $2 \%$ (selon Helsana et CSS).

Une croissance plate n'est pas une envolée des coûts mais l'expression d'objectifs fixés au niveau politique atteints avant l'heure.

Ce qui est surprenant est que ces supposées «sombres prophéties» émergent alors que les objectifs politiques d'austérité sont atteints avant l'heure! Le rapport du groupe d'experts du Conseil fédéral préconise de limiter "à long terme» l'augmentation des primes de l'AOS "à 2,7\% par an", au lieu des $4 \%$ en moyenne actuels [4]. Les experts avaient proposé de limiter la croissance dans un premier temps «à 3,3\% (...) avant de la réduire à 2,7\%» [4] pour prendre en compte le temps nécessaire pour que les mesures fassent effet.

L'augmentation moyenne de 3,4\% enregistrée pendant cinq ans avant 2017 correspond déjà à l'objectif intermédiaire de 3,3\% avec budget global prévu pour 2021, et cela sans avoir mis en place cette bureaucratie budgétaire pesante. La croissance des coûts de 2,6\% en 2017 est même inférieure à l'objectif de 2,7\% visé par les politiques à partir de 2026.

Que faut-il en déduire? Premièrement: l'évolution des coûts peut, de toute évidence, être ralentie sans mettre en place une régulation et une administration. Deuxièmement: établir un budget n'est pas une science exacte. Rappelons, pour l'illustrer, que les projections de santésuisse [5] et l'augmentation des primes approuvée par la Confédération pour 2018 [6] étaient de 4\%, nettement supérieure à la hausse réelle (seulement $0,2 \%$ environ) [7]. Vu que moins d'argent a été nécessaire pour la prise en charge médicale qu'estimé, un demi-million d'assurés bénéficieront cette année d'un remboursement de leurs primes et les réserves des caisses seront augmentées. Les conséquences seraient plus désagréables si, avec un budget global défini par des experts nommés par les politiques, les soins de santé devenaient plus chers: cela aboutirait à un rationnement des soins.

Certes, une ligne de croissance aussi minime soit-elle indique une augmentation et une hausse des primes. Là aussi, l'OFS donne des informations positives: la hausse des primes ne diminue pas le revenu des ménages suisses, elle en diminue exclusivement la croissance de 0,3 point [8]. Sans augmentation des primes, le revenu mensuel moyen disponible aurait augmenté de 142 francs entre 2017 et 2018. Avec l'augmentation des primes, il est passé de 4139 à 4267 francs, soit une augmentation de 128 francs [8]. Malgré cette évolution, les ménages suisses aux revenus les plus faibles ont davantage d'argent qu'auparavant [9], même si cela reste encore trop peu.

La FMH interprète le ralentissement observé de la hausse des coûts comme un mandat l'incitant à poursuivre ses efforts en vue de garantir des soins de santé abordables et une utilisation efficace des ressources

Les projections des coûts et les augmentations des primes ont été surestimées en 2017 et 2018.

dans le secteur de la santé. Le fait que le budget global s'avère déjà superflu nous encourage dans ce sens, d'autant plus que son introduction serait très coûteuse sur le plan administratif. 